\title{
Parameters setting and verification of 5-axis machine with multiple axes rotary spindle head based on Master CAM X
}

\author{
Li Guan ${ }^{1, \text { a }, ~ X u-x i a n g ~ Z h a n g ~}{ }^{2, b}$ \\ ${ }^{1}$ Wuhan Institute of Technology, Hubei, Wuhan 430073,China \\ ${ }^{2}$ Wuhan Polytechnic, Hubei, Wuhan 430073,China \\ a810871452@qq.com, bxxwit@126.com
}

\begin{abstract}
Key words: multiple axes rotary spindle head; post processing; parameter modification; five axis machining

Abstract: According to Generic Fanuc 5X Mill.pst post processing document and the discussion on modification method of main parameters of X Master CAM version five axes machining with double pendulum head, this paper compares manual calculation data of holes nodes with the automatic generation program after modification, and verifies the rationality of the main parameters modification in the post processing.
\end{abstract}

\section{Introduction}

Due to its complex spatial concept of 5-axis machining, it's difficult to directly check the program coordinate data obtained from automatic programming. Therefore, how to deal with its subsequent processing needs to be carefully considered. It's usually solved with the compensable service. The development of the five axis machining technology is more or less restricted for its considerable cost [1,2]. It's found in exploring 5-axis post processing parameter Settings that there are set items suitable for various kinds of 5-axis configuration solutions in the post processing documents CAM provides. Users don't easily modify those set items mainly for its difficult to judge the rationality of the revised program output[3]. From 5-axis drilling node coordinates manual calculation, this article deals with the comparison of program combined with post-processing main parameters modification of 5-axis machine with multiple axes rotary spindle head based on Master CAM X to explore its rationality.

\section{Analysis of Drilling Program Characteristics of 5-axis Machine with Multiple Axes Rotary Spindle Head}

The five axis machine with double pendulum head is as shown in fig.1. Its swing length $\mathrm{L}$ consists of $\mathrm{H}$ (the distance from the pivot point to the spindle nose end) and L0 (the fixed length of the cutter) two parts. If the 5-axis machine with double pendulum head is used to process the hole on the box parts, the work piece angle cannot be rotated so that it's unable to realize the requirements of each parallel hole axis and $\mathrm{Z}$ axis. Therefore, it is difficult to use the drilling cycle instructions to process the hole[4]. The main shaft head can be used to achieve the orientation where the cutter axis parallel to the axial direction of each hole. If the cutter axis parallel to the $\mathrm{X} / \mathrm{Y} / \mathrm{Z}$ axis, drilling and boring cycle instructions can be used after G17、G18、G19 planes

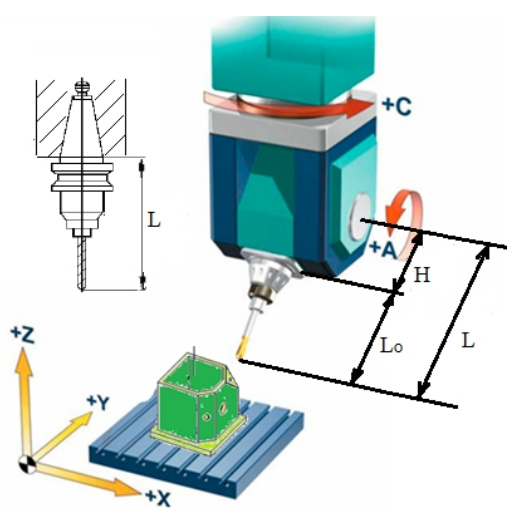

Fig.1 Swing length of double pendulum head machine switch. While, the rest can only use basic command G00 / G01 to control X/Y/Z synthesis movement for hole processing. 


\section{Manual Algorithms for Drilling Nodes Coordinate of 5-axis Machine with Multiple Axes Rotary Spindle Head}

As shown in Fig.2, it is an engineering drawings of a box body parts. Among it, the three holes Ф50、Ф20、 $\Phi 18$ are needed in 5-axis machine to process. A dynamic shaft needs to set the turn $90^{\circ}$ to make knife axis parallel to the hole axis Shaft during the process of box holes $\Phi 50$ 、 $\Phi 20$ in the way of multiple axes rotary spindle head. At this time, the work piece in the $\mathrm{X} / \mathrm{Y}$ direction need to have enough distance from the fixed axis for the implementation of the drilling process. Therefore, it's better that $\Phi 50$ hole axis and $\mathrm{X}$ axis are arranged in parallel when clamping box parts in order to make full use of the bed table $\mathrm{X}$ travel range and prevent problems for insufficient Y range.
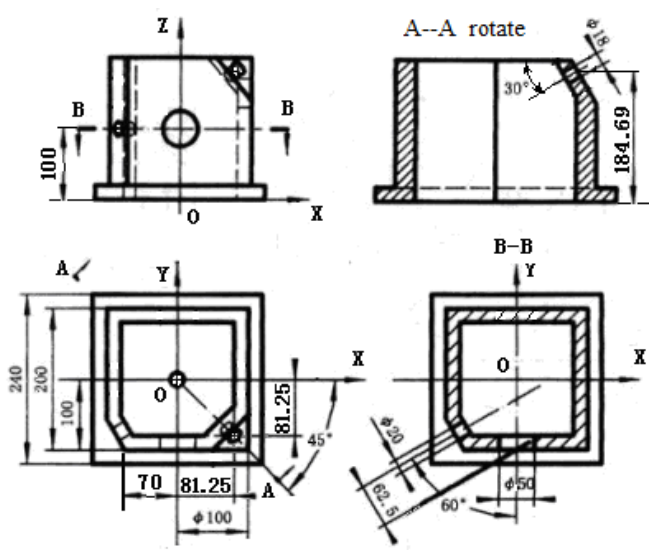

Fig.2 Box part's engineering drawings

Suppose the distance between the nose and the end of a machine is 120, the length of the center drill tool is 180 , and its swing length $\mathrm{L}$ is $120+180=300$. The center of the bottom surface of the box body parts serves as the zero point of the work piece, and that tool is used to make $2 \mathrm{~mm}$ depth holes. The coordinate relation of the hole position is calculated as follows:

When processing the $\Phi 50$ hole, $\mathrm{A}=90^{\circ}, \mathrm{C}=90^{\circ}, \mathrm{Y}=0$; the coordinates for $\mathrm{X}$ and $\mathrm{Z}$ can be calculated as geometry relations shown in Figure 3(a). That is, $X=100-2+180+120=398$, $\mathrm{Z}=100-\mathrm{L}=100-300=-200$.

When processing the $\Phi 20$ hole, $\mathrm{A}=90^{\circ}, \mathrm{C}=30^{\circ}, \mathrm{Z}$ coordinate is same to that of $\Phi 50$ hole, namely $\mathrm{Z}=-200$. The coordinates for $\mathrm{X}$ and $\mathrm{Y}$ can be calculated as geometry relations shown in Figure 3(b).

It can be known from the size relations in Figure 2, in Fig.3(b), oa=100, ad=70, $c f=62.5$. It can be calculated as follows:

$\mathrm{af}=\mathrm{ad} \times \cos 30^{\circ}=60.622, \mathrm{fb}=\mathrm{cf} \times \operatorname{tg} 30^{\circ}=36.084, \mathrm{ae}=\mathrm{bc}=\mathrm{cf} / \cos 30^{\circ}=72.169$

$\mathrm{oe}=100-\mathrm{ae}=27.831, \mathrm{ce}=\mathrm{ab}=\mathrm{af}+\mathrm{fb}=60.622+36.084=96.706$

When processing the $\Phi 20$ hole, $\mathrm{X}=\mathrm{oe}+(\mathrm{ce}-2+\mathrm{L}) \times \sin 30^{\circ}=225.184, \mathrm{Y}=-(\mathrm{ce}-2+\mathrm{L}) \times \cos 30^{\circ}=-341.826$

The point that is $10 \mathrm{~mm}$ from orifice is taken as the initial position of drilling, and the $\mathrm{X} 0$, Y0 coordinates can be calculated as follows:

$\mathrm{X}_{0}=\mathrm{oe}+(\mathrm{ce}+10+\mathrm{L}) \times \sin 30^{\circ}=231.184, \mathrm{Y}_{0}=-(\mathrm{ce}+10+\mathrm{L}) \times \cos 30^{\circ}=-352.218$

When processing the $\Phi 18$ hole, $\mathrm{A}=60^{\circ}, \mathrm{C}=135^{\circ}$. Drilling process requires $\mathrm{X} / \mathrm{Y} / \mathrm{Z}$ linkage feed motion, therefore, it's necessary to calculate $\mathrm{X}, \mathrm{Y}, \mathrm{Z}$ coordinates of those two points before and after drilling feeding, geometry calculation is as shown in Fig.3.

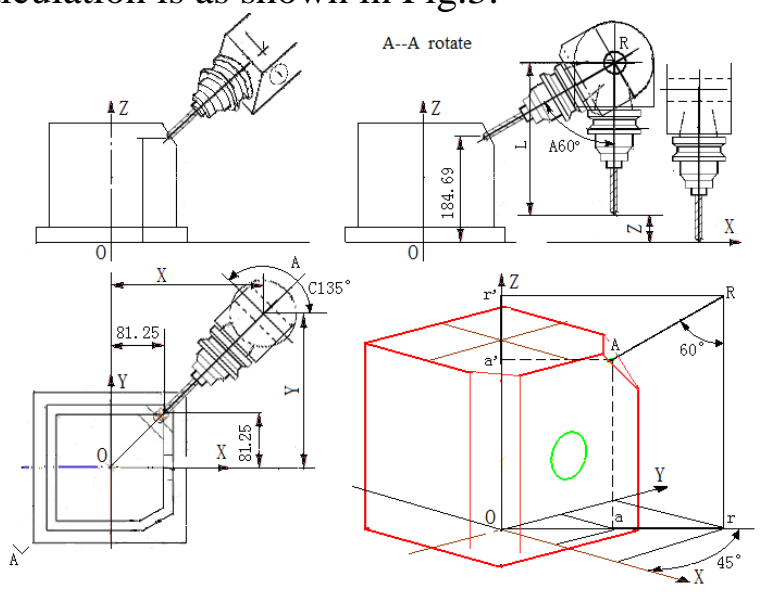

Fig. 3 computational geometry diagram of $\Phi 18$ hole position calculation 
In the Fig.3, the orifice center A coordinates (81.25, 81.25184.69), AR=L-2=298, it can be calculated:

ar $=\mathrm{AR} \times \sin 60^{\circ}=258.0756, \mathrm{a}^{\prime} \mathrm{r}^{\prime}=\mathrm{AR} \times \cos 60^{\circ}=149$,

then the coordinates of $\mathrm{R}$ point are as follows:

$\mathrm{Xr}=\mathrm{Yr}=81.25+\mathrm{ar} \times \sin 45^{\circ}=263.737, \mathrm{Zr}=184.69+\mathrm{a}^{\prime} \mathrm{r}^{\prime}=333.69$

When processing the $\Phi 18$ hole, $\mathrm{X}=\mathrm{Xr}=263.737, \mathrm{Y}=\mathrm{Yr}=263.737, \mathrm{Z}=\mathrm{Zr}-\mathrm{L}=33.69$

The point that is $10 \mathrm{~mm}$ from orifice is taken as the initial position of drilling, and the $\mathrm{X}_{0}, \mathrm{Y}_{0}$ coordinates can be calculated as follows:

$\mathrm{X}_{0}=\mathrm{Y}_{0}=81.25+(\mathrm{AR}+12) \times \sin 60^{\circ} \times \sin 45^{\circ}=271.086$,

$\mathrm{Z}_{0}=184.69+(\mathrm{AR}+12) \times \cos 60^{\circ}-\mathrm{L}=39.69$

\section{Parameter modification of Post Processing Document for the 5-axe with Double Pendulum Head}

Five axis parameters based on Master CAM X version is set in 5 Axis Rotary Settings section of PST document. It mainly comprises a rotating shaft code, the positive direction, the head/swing table configuration for five axis, axial offset or pendulum length, rotation axis angle limit parameters, etc.. Based on Generic Fanuc 5X Mill.pst post processing document, the five axes with double pendulum head are provided with the modification of main parameters according to the preceding $\mathrm{C}+\mathrm{A}$ mode, as shown in Table1.

Table 1. Double pendulum head C + A five-axis main parameter setting and meaning

\begin{tabular}{|c|c|c|c|c|c|}
\hline main set & $\begin{array}{c}\text { str_pri_axis } \\
\text { "C" } \\
\text { str_sec_axis } \\
\text { "A" }\end{array}$ & mtype : 2 & $\begin{array}{c}\operatorname{rotaxis} 1 \$=\text { eecy, } \\
\operatorname{rotdir} 2 \$=\text {-vecx } \\
\operatorname{rotaxis} 2 \$=\text { eecz } \\
\operatorname{rotdir} 2 \$=\text {-vecy }\end{array}$ & $\begin{array}{c}\text { top_type } \\
: \mathbf{3}\end{array}$ & $\begin{array}{c}\text { toollength : } \mathbf{3 0 0} \\
\text { shift_z_pvt : } \mathbf{1}\end{array}$ \\
\hline $\begin{array}{c}\text { meaning } \\
\text { description }\end{array}$ & $\begin{array}{l}\text { The output } \\
\text { leading } \\
\text { character of } \\
\text { the first / } \\
\text { second rotary } \\
\text { shaft is } \\
\text { provided as } \\
\text { C/A }\end{array}$ & $\begin{array}{c}\text { Five axis } \\
\text { structure } \\
\text { mode.0: } \\
\text { Double } \\
\text { pendulum } \\
\text { station, 1: } \\
\text { pendulum head } \\
+ \text { table, 2: } \\
\text { double } \\
\text { pendulum head }\end{array}$ & $\begin{array}{l}\text { The first shaft } \mathrm{C} \text { seems } \\
\mathrm{y} \text { position direction as } \\
\text { zero point, and - } \mathrm{x} \text { as } \\
\text { position direction; the } \\
\text { secong shaft A seems } \mathrm{z} \\
\text { position direction as } \\
\text { zero point, and -y as } \\
\text { position direction; }\end{array}$ & $\begin{array}{c}\text { Knife } \\
\text { axis } \\
\text { plane。 } \\
1: \mathrm{A}+\mathrm{C} \\
; \\
2: \mathrm{B}+\mathrm{C} \\
; \mathbf{3} \\
\mathrm{C}+\mathrm{A} ; \\
4: \mathrm{C}+\mathrm{B}\end{array}$ & $\begin{array}{l}\text { pendulum } \\
\text { length: } 300 \\
\mathrm{Z} \text { offset, } 0: \\
\text { According to the } \\
\text { pivot point; } 1 \text { : } \\
\text { According to the } \\
\text { pendulum } \\
\text { length: } 2 \text { : } \\
\text { According to the } \\
\text { nose }\end{array}$ \\
\hline
\end{tabular}

\section{Comparison and verification of automatic programming of double pendulum head with five} axes

Based on Master CAM X version, it's necessary to establish a model and design the tool path for five axes drilling, and then related them to the post processing file established after parameters modification. Then NC procedures can be obtained automatically:

O0001 ( PROGRAM - drilling and boring )

N104 G0 G17 G40 G80 G90 G94 G98 Initialization mode

N112 T1 M6 select T1 tool

N114 G0 G54 G90 X410. Y0. C90. A90. S1000 M3 locate the initial position of X/Y/C/A to the point10mm from $\Phi 50$ hole

N116 G43 H1 Z-200. M8 height of $\mathrm{Z}$ axis when drilling $\Phi 50$ hole

N118 G19 G81 G99 X398. R410. F50. switch to G19 plane and drill $\Phi 50$ hole in cycle with -2mm in depth 
N122 G80

N124 G17 X231.184 Y-352.218 C30.

exit the drilling cycle mode

locate the initial position of $\mathrm{X} / \mathrm{Y} / \mathrm{C}$, A remains the same

N126 G1 X225.184 Y-341.826

N128 G0 X231.184 Y-352.218

N130 X256.184 Y-395.52

N132 X271.086 Y271.086 Z39.69 C135. A feeding the hole $\Phi$ 20until the termination position with depth $-2 \mathrm{~mm}$ of $\mathrm{X} / \mathrm{Y}$ make X/Y back to the start position of the hole $\Phi 20$ rewind a safe distance along $\Phi 20$ axis

N134 G1 X263.737 Y263.737 Z33.69 feeding hole Ф18until the termination position with depth -2mm of $\mathrm{X} / \mathrm{Y} / \mathrm{Z}$

N136 G0 X271.086 Y271.086 Z39.69 M9 make X/Y /Z back to the start position of the hole $\Phi 20$

N140 M5

N142 G0 G28 G91 Z0.

N144 G0 G28 X0. Y0.

N146 G28 C0. A0.

N148 M30

Through the analysis of procedures above and comparison of manual node calculation results, it is not difficult to conclude that, the cutter axis is parallel to $X$ axis when processing the $\Phi 50$ hole, and it's realized by G81 drilling and boring cycle after NC program switching to G19 plane. The remaining two holes are completed in G00/G01. After processing the $\Phi 20$ hole, there is a retract node with a safe distance. Among NC programs above, all nodes are fully consistent with manual calculation results but the retract node that is difficult to make a judgment. It can be concluded that the modification of the 5-axis post processing parameters with double pendulum head is reasonable and feasible.

\section{Conclusions}

For Master CAM X version, the design of 5-axis machine tool path has nothing to do with the use of machine. There are a variety of 5-axis configuration programs in the post processing document whose parameters settings can be modified. According to the author's experience using the Master CAM X version, what it needs to determine whether the 5-axis post processing is reasonable or not is a simple 5-axis drilling case. Being familiar with the hole coordinates manual algorithm under corresponding five axis modes and checking the key coordinate data in output program after modification are enough instead of complex multi axis simulation software. As long as the five axis drilling automatic program is validate, there is no principle error in other basic line or circular interpolations, reasonable designs of the surface milling and other dates. As for the interference result from unreasonable tool path, it isn't supposed to be related to rationality of machine configuration scheme modification. The rationality of the cutter path design and the judgment of the interference collision possibility must be further verified with the simulation software.

\section{Acknowledgements}

This work was financially supported by the key projects of Hubei Provincial Department of Education (D20131507) and the Sixth Graduate Education Innovation Fund of Wuhan Institute of Technology(CX2014031).

\section{References}

[1] Man-cai He CNC programming and machining-9.0 example explanation Master Cam [M]. Beijing: Posts and Telecom Press, 2004.

[2] Ming Wei, Wei-min Liu. Mastercam9.0 mold design and processing [M]. Beijing: Posts and Telecom Press, 2004. 
[3] Mu-wu Su. Advanced programming method and application of Master CAM post processing file [J]. Manufacturing Technology \& Machine Tool. 2006, (1):17-20.

[4] Chun-lan Liu, Pei-wen Lu. Analysis of multi axis machining of curved surface based on Master CAM [J]. CAD/CAM and manufacturing informatization, 2010,(9):71-73. 